\title{
Analysis of Coupling the Pesticide Use Reduction with Environmental Policy for Agricultural Sustainability in Taiwan
}

\author{
Wen-Tien Tsai ${ }^{1}$ \\ ${ }^{1}$ Graduate Institute of Bioresources, National Pingtung University of Science and Technology, Pingtung, Taiwan \\ Correspondence: Wen-Tien Tsai, Graduate Institute of Bioresources, National Pingtung University of Science \\ and Technology, Pingtung 912, Taiwan. Tel: 886-87-703-202. E-mail: wttsai@mail.npust.edu.tw
}

$\begin{aligned} & \text { Received: November 22, } 2012 \\ & \text { Accepted: January 5, } 2013 \quad \text { Online Published: March 18, } 2013 \\ & \text { doi:10.5539/ep.v2n2p59 }\end{aligned} \quad$ URL: http://dx.doi.org/10.5539/ep.v2n2p59

\begin{abstract}
As Taiwan has a dense population and only limited natural resources, the government began actively establishing a Taiwan's sustainable development indicators (TSDI) system in 2003 to evaluate the progress towards sustainability. Commonly used pesticides could pose a risk of causing adverse effects to food sanitation, human health and the environment. Thus, the pesticide usage rate per hectare of farmland and the area of organic cultivation have been selected as agricultural sustainability indicators. The objective of this paper was to describe an analysis of current status of pesticide use and regulatory policy for environmental sustainability in Taiwan. Furthermore, it can be connected with the regulatory infrastructure, which has been established by the joint-venture of the central competent authorities (i.e., Council of Agriculture, Environmental Protection Administration, Department of Health, Ministry of Economic Affairs, and Council of Labor Affairs) for controlling and/or preventing pesticide distribution in the environment. The significant progress is that the residual pesticides have notably declined in the past decade, which was in parallel with the pesticide usage rate decreased and organic farming area increased. For example, total area of organically certified cropping in Taiwan has been increased from 900 hectares (ha) in 2001 to about 4,500 ha in 2010. Finally, some recommendations for the pollution prevention and toxicity reduction of pesticide use were also addressed to progress towards a sustainable agriculture in Taiwan.
\end{abstract}

Keywords: pesticide, sustainable development indicator, legislation, risk reduction

\section{Introduction}

In the past decades, pesticides have been extensively used to intentionally kill a wide range of unwanted organisms. Besides target pests (e.g., insects, rodents, nematodes, ticks and mites), weeds and fungi, they also affect wildlife and human health by destroying biochemical and physiological properties, and spreading disease or vector. Although there are positive benefits to the use of pesticides in promoting agricultural production, some also have drawbacks or side-effects, such as potential toxicity to humans and other animals, and negative impacts on the ecological environment (Oluwole \& Cheke, 2009). The toxcity of a pesticide can be either acute or chronic, including those toxic effects on hematopoietic system, immune system, carcinogenesis etc. For example, many recent studies have been focused on the potential hormone-like effects of a great diversity of pesticides on the endocrine systems of wildlife and humans (Amaral-Mendes, 2002). The endocrine and reproductive effects of these chemicals are believed to have similar effects as the endogenous estrogens. Today, these chemicals are collective terms of endocrine disrupting chemicals (EDCs), endocrine disruptors or environmental estrogens.

Since the 1960s, the risks posed by pesticides have become of increasing concern in international communities. These pesticides are known to be widely used as insecticide, herbicide, fungicide, acaricide and nematicide. It should be noted that they were applied in agriculture and transported to the environment by means of runoff and infiltration, causing the deterioration of water sources and soils. They may also contaminate sources of food or crops. Furthermore, pesticides may come into direct contact with wildlife, even causing death or injury. They may disrupt internal hormonal regulation making physiological and behavioral changes. As a result, most countries developed management systems (e.g., organic farming) to regulate the use and abuse of pesticides (Dent, 2005), which will meet higher environmental and health standards. Therefore, removal of residual pesticide from aqueous environment is of an increasing concern. Meanwhile, concerns about the persistence of 
certain organic products like organochlorine pesticides had been growing. Several regional and global treaties and/or initiatives have been negotiated for identifying persistent pesticides and developing risk management measures to reduce the exposure of humans and the ecosystem to these toxic substances (Pretty \& Hine, 2005).

In the United States, the U.S. Environmental Protection Agency registers pesticides under the Federal regulations, including the Federal Insecticide, Fungicide and Rodenticide Act (FIFRA) and the Federal Food, Drug and Cosmetic Act. The registration process includes product efficacy assessments, assessments of risks to human health and ecological risk assessments (Lydy et al., 2004). Taiwan, located in the southeastern rim of Asia, is a densely populated island country (i.e., population density: 640 people $/ \mathrm{km}^{2}$; total area: $36000 \mathrm{~km}^{2}$ ). Therefore, this country has warm and humid climate that is liable to the occurrence of plant diseases and insect pests. Unavoidably, farmers in Taiwan are used to control plant diseases and pests with relatively high rates of synthetic pesticides. To reduce risks as a result of using chemical pesticides, the Pesticide Management Act in Taiwan has been revised several times since it was promulgated and implemented in 1972. This Act is enacted to protect agricultural production and ecological environment, prevent and eliminate pests, prevent hazards from pesticides, strengthen pesticide administration, promote the development of pesticide industry, and enhance the safety of agricultural products. The Bureau of Animal and Plant Health Inspection and Quarantine (BAPHIQ) under the Council of Agriculture (COA) shall take responsible to the task of pesticide management such as registration and safety assessment. On the other hand, the Taiwan Agricultural Chemicals and Toxic Substances Research Institute (TACTRI) is authorized by COA to perform pesticide residual analysis, quality specification analysis, and also evaluate toxicology and risk for registration of new pesticides. Other central competent authorities, including the Environmental Protection Administration (EPA) and the Department of Health (DOH), have also promulgated relevant regulations to ban or restrict toxic and persistent pesticides, or start the investigation for monitoring their environmental concentrations and residual levels in food. For example, many pesticides were banned for use under the Pesticide Management Act and the Toxic Chemical Substances Control Act. In summary these regulatory measures attempt to achieve an agricultural industry that is not only more profitable but also environmentally sustainable.

Although integrated pest management (IPM) and biological control (BC) programs are increasingly recognized and promoted as viable alternatives, the regulatory and non-regulatory approaches in Taiwan for the use of pesticides will be expected to offer prevention strategies for other developing and developed countries. In line with the public concern about the human health risk on the pesticide and its intoxication, the objectives of this paper were to survey the situations of pesticide use and its environmental sustainability indicator in illustration of the regulatory infrastructure of reducing its discharge into the environment of Taiwan.

\section{Method}

Just like fertilizers, the agricultural production highly depends on the input of pesticides for pest management and thus for crop production. As a result, it is impractical to measure every non-point source in the urban environment. The discharges of pesticides into the environment are generally estimated from the activity rate or consumption. The anthropogenic activity (consumption) data may be extracted from the official yearly statistical information from the ministry-level organization under the Taiwanese Cabinet. These data on activity (consumption) and regulation measures are briefly summarized below.

\subsection{Activity (Consumption) of Pesticide}

Activity database was compiled from the Annual Statistics of Directorate General of Customs (Ministry of Finance, Taiwan; http://www.customs.gov.tw/StatisticsWebEN/IESearch.aspx) and the Annual Statistics of Bureau of Animal and Plant Health Inspection and Quarantine (Council of Agriculture, Taiwan; http://pesticide.baphiq.gov.tw/web/Insecticides_MenuItem9_1S.aspx). In this work, the consumption of pesticide in Taiwan can be roughly obtained by the data on the sale quantities.

\subsection{Regulation Measures of Reducing Pesticide Use}

In order to analyze the consumption trend of pesticide from agricultural sector and its residual status in the aquatic environment, the regulatory infrastructure of reducing its discharge into the environment of Taiwan was extracted from the official websites of the ministry-level organizations under the central competent authorities, including the Council of Agriculture (COA), the Department of Health (DOH), the Council of Labor Affairs (COLA), the Environmental Protection Administration (EPA), and the Ministry of Economic Affairs (MOEA). 


\section{Results and Discussion}

\subsection{Current Status of Pesticide Use}

Placing in line with the international treaties and/or environmental pollution efforts since the early 1970s, the Taiwan government promulgated relevant regulations for banning the production, import, sale, and use of some pesticides, which were widely used as insecticides under the authorization of the Pesticide Management Act. Also, some pesticides have been designated as "use-restricted pesticides" under the authorization of the Act. The pesticide in Taiwan had been registered by the central competent authority till December 31, 2003. BAPHIQ takes responsibility for the tasks of pesticide management since 2004, including the registration, manufacturing, import, export, permit, safety assessment, and selling of the registered pesticide. On the other hand, one of the agricultural policies in Taiwan is to develop organic farming and integrated pest management for healthful agriculture in recent years, and to put Taiwan become a toxin-free agricultural island. As compared to the data on 159 hectares (ha) in 1996 and around 2,200 ha in the early 2008, the total area of organically certified cropping in Taiwan was on the increasing trend to 4,217 ha till May 2010, which included rice (1,384 ha), vegetable (1,439 ha), fruit (508 ha), tea (248 ha) and others (638 ha).

In Taiwan, most of the technical-grade pesticides are imported from abroad, and then formulated into commercial products in market. As listed in Table 1 (COA, 2012), approximately 9,228 tons of pesticides based on their active ingredients were consumed in 2005, which was equivalent to the sale value of around US\$ 155 million. With the sustainable agriculture implemented, the total quantities of pesticide consumption were on decreasing trend in recent years, showing that the decline rate at about $15 \%$ was observed in comparison with the data of 9,228 tons in 2005 and 8,254 tons in 2011. However, the sale values of pesticides increased from US\$ 155 million in 2005 to US\$ 191 million in 2011. On the other hand, the increasing sales value from 155 million US\$ in 2005 to 292 million US\$ in 2010 could be attributed that the farmers used more expensive pesticide products which are effective at lower application rates. Although the quantity of insecticides ranked top in the 1990s, the use of herbicides has increased rapidly in the early 2000. For example, herbicides accounted for $38.6 \%$ of total quantity, insecticides $33.8 \%$ and fungicides $25.3 \%$ in 2005 . It should be noted that the proportions and quantities of pesticide consumption have been changed to be in response to the agricultural policy for organic farming and the biological pest management (Toleubayev et al., 2011), and the increasing price of pesticide. It would be helpful to use farm survey data on the number of treatments.

Table 1. The statistics of consumption for pesticides in Taiwan since $2005^{\mathrm{a}}$

\begin{tabular}{ccccccccc}
\hline Year & Acaricide & Fungicide & \multicolumn{7}{l}{ Herbicide Insecticide } & \multicolumn{2}{l}{ Nematicide Others } & $\begin{array}{c}\text { Quantity of } \\
\text { Pesticide usage }\end{array}$ & $\begin{array}{c}\text { Value } \\
\text { (million US\$) }\end{array}$ \\
\hline 2005 & 150 & 2,254 & 3,564 & 3,177 & 28 & 55 & 9,228 & 155 \\
2006 & 141 & 1,983 & 3,859 & 2,948 & 21 & 63 & 9,015 & 158 \\
2007 & 153 & 2,306 & 3,905 & 3,029 & 27 & 72 & 9,492 & 176 \\
2008 & 161 & 2,487 & 3,006 & 3,008 & 26 & 95 & 8,782 & 191 \\
2009 & 127 & 2,210 & 3,396 & 2,756 & 34 & 66 & 8,589 & 229 \\
2010 & 143 & 1,965 & 2,713 & 2,917 & 42 & 71 & 7,852 & 292 \\
2011 & $(255)^{\mathrm{b}}$ & 2,054 & 2,984 & 2,964 & -- & -- & 8,254 & 191 \\
\hline
\end{tabular}

${ }^{\text {a }}$ Based on the quantity of active ingredient (unit: metric ton) and its value (million US\$, 1 NT $\fallingdotseq \fallingdotseq 0.033$ US\$).

${ }^{\mathrm{b}}$ Including acaricide, nematicide and others.

\subsection{Sustainable Development Indicators Relating to Pesticide Use}

To be in accordance with the trend of "Sustainable Development" first revealed by the World Commission on Environment and Development (WCSD) in 1987, the Taiwanese government consequently began to establish a Taiwan's sustainable development indicators (TSDI) system for evaluating the progress in promoting 
environmental sustainability (Hess, 2011). The National Council for Sustainable Development (NCSD) of Taiwan made joint efforts with the related ministries to actively establish the TSDI system since 1998. A set of 99 sustainability indicators, which are most representative of 12 themes (including environment, energy conservation \& carbon reduction, national land resource, biodiversity, production, livelihood, health, science \& technology, urban \& rural culture, wellbeing, governance, participation), were recently selected to reform the Second Edition TSDI system in 2009. However, the indicators in the new TSDI system concerning the agricultural sustainability in the production theme contain the ratio of cultivated land, area of organic cultivation, fertilizer usage rate per hectare of farmland, and pesticide usage rate per hectare of farmland.

According to the Annual Evaluation Reports on Sustainable Development Indicators in 2010, the pesticide usage rate per hectare of farmland has significantly decreased in the past decade due to the government policy and regulatory system for pesticide management towards a more sustainable agriculture as described below (NCSD, 2011). As a result, the agricultural sustainability indicator has gradually decreased from $1.26 \mathrm{~kg} / \mathrm{ha}$ in 2004 to $0.97 \mathrm{~kg} / \mathrm{ha}$ in 2010 (Table 2). On the other hand, the area of organic cultivation for producing chemical-free safe crops and food significantly increased from $12.46 \mathrm{~km}^{2}$ in 2001 to $40.34 \mathrm{~km}^{2}$ in 2010 as shown in Figure 1, showing that the organic farming in Taiwan has experienced a positive way toward agricultural sustainability. Under the regulatory promotion and consumer awareness, the plant protection practices on these organic farming areas could have gradually affected those used for conventional agriculture. More significantly, residual pesticides have notably declined in the past decade. For example, based on the monitoring results surveyed by the Taiwan Agricultural Chemicals and Toxic Substances Research Institute (TACTRI) in 2005, the environmental distribution of residual paraquat seemed to be negligible in recent years (Shyu \& Lee, 2006).

Table 2. The statistics of pesticide usage and organic cultivation in Taiwan since $2004^{\mathrm{a}}$

\begin{tabular}{|c|c|c|c|c|c|c|c|}
\hline Year & $\begin{array}{l}\text { Imported } \\
\text { pesticide }\end{array}$ & $\begin{array}{r}\text { Domestic } \\
\text { pesticide }\end{array}$ & $\begin{array}{l}\text { Exported } \\
\text { pesticide }\end{array}$ & $\begin{array}{c}\text { Pesticide } \\
\text { usage }\end{array}$ & $\begin{array}{l}\text { Farmland } \\
\text { area }\left(\mathrm{km}^{2}\right)\end{array}$ & $\begin{array}{l}\text { Pesticide usage } \\
\text { rate (ton } / \mathrm{km}^{2} \text { ) }\end{array}$ & $\begin{array}{c}\text { Organic cultivation } \\
\text { area }\left(\mathrm{km}^{2}\right)\end{array}$ \\
\hline 2004 & 2,821 & 11,618 & 3,947 & 10,492 & 8,355 & 1.26 & 12.46 \\
\hline 2005 & 2,839 & 9,835 & 2,784 & 9,890 & 8,332 & 1.19 & 13.35 \\
\hline 2006 & 2,305 & 8,506 & 1,944 & 8,867 & 8,295 & 1.07 & 17.08 \\
\hline 2007 & 2,815 & 8,900 & 2,224 & 9,491 & 8,259 & 1.15 & 20.13 \\
\hline 2008 & 2,592 & 8,838 & 2,648 & 8,782 & 8,224 & 1.07 & 23.56 \\
\hline 2009 & 2,522 & 8,140 & 2,074 & 8,588 & 8,155 & 1.05 & 29.60 \\
\hline 2010 & 2,280 & 7,882 & 2,310 & 7,852 & 8,131 & 0.97 & 40.34 \\
\hline
\end{tabular}

\footnotetext{
${ }^{a}$ Based on the quantity of active ingredient in pesticide (unit: metric ton).
} 


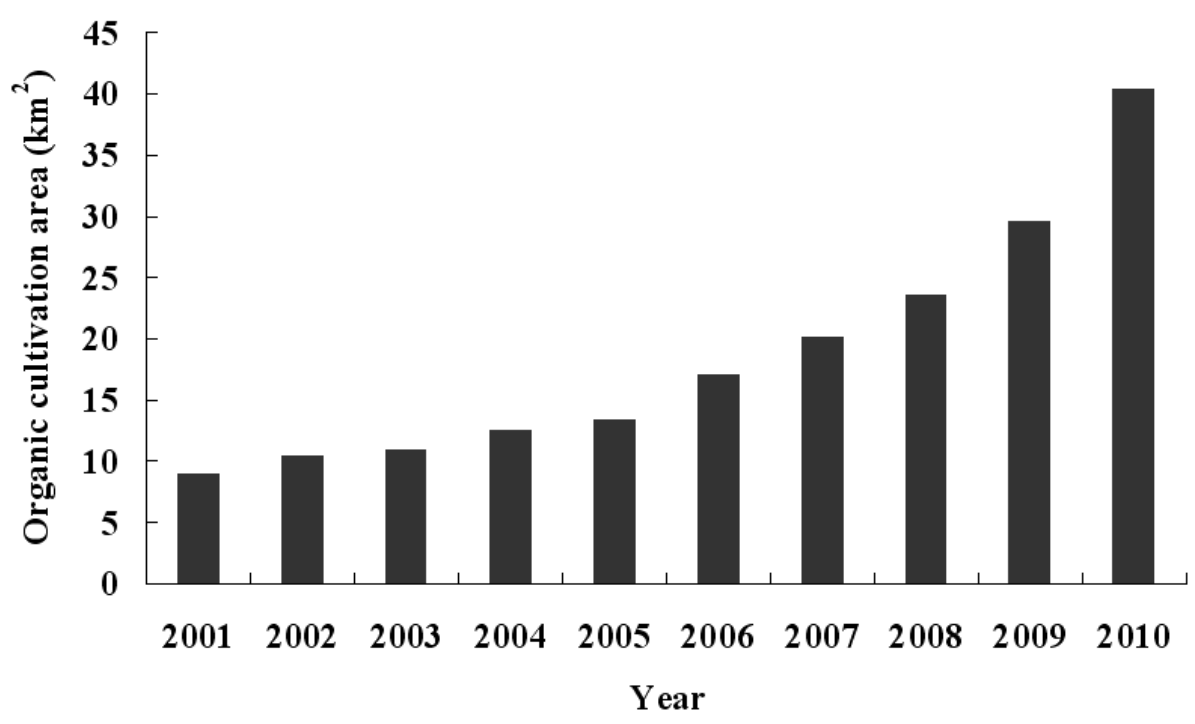

Figure 1. The area of organic cultivation of Taiwan in the past decade

\subsection{Governmental Policy towards a More Sustainable Agriculture}

The necessity of ecologically farming systems coupled with the desire for foods free from synthetic chemicals (e.g., pesticide and fertilizer) has made organic farming one of the fastest-growing agricultural enterprises (Katsvario et al., 2007). Concerning the environmental sustainability in Taiwan, one of the Construction Amendments refers to the following statement: Environmental and ecological protection shall be given equal consideration with economic and technological development. Under the principle of the Construction Amendments, the Taiwan government has set some acts/laws pertaining to pesticide management, and measures for the purpose of pursuing a balance between economic development and environmental sustainability since the late 1990s.

It is well known that organochlorine pesticides (OCPs) are capable of persisting in the environment, transporting between phase media and accumulating to levels in the environment, implying that they could pose a risk of causing adverse effects to human health and the environment. Therefore, most of OCPs are designated as persistent organic pollutants (POPs) and even endocrine disrupting chemicals (EDCs). In the face of the Stockholm Convention on the persistent organic pollutants (POPs), the Taiwanese government has begun to establish interactive models for industry, citizen, government, academia and research organizations to take greater involvement in POPs environmental surveillance \& monitoring and destruction \& reduction technologies. Thereafter, the "National Implementation Plan of Republic of China (R.O.C., Taiwan) under the Stockholm Convention on Persistent Organic Pollutants" has been passed by the Executive Yuan in Jul. 2008, although Taiwan is currently not a party of the Convention (EPA, 2008). This plan (i.e., NIP) both seeks to service as a basis for national implementation work and to highlight Taiwan's control strategies and proactive measures in dealing with POPs.

\subsection{Regulatory System of Controlling Pesticide Use}

Residual pesticide is probably a problem that worries consumers the most when they buy agricultural products. Also, the public concern about pesticides in the environment and their impacts on human health is rising. As a result, there is a push on promulgating the legislative frameworks for controlling/restricting their uses and distributions based on the environmental, food and health risks posed by these chemicals. Therefore, the central authorities and relevant laws/acts in Taiwan pertaining to the pesticide use, residual limit, exposure standard, and its preventive measures include

(1) Environmental Protection Administration (EPA)

Toxic Chemical Substances Control Act (TCSCA), Water Pollution Control Act (WPCA), Soil and Groundwater Pollution Remediation Act (SGPRA), Drinking Water Management Act (DWMA), Marine Pollution Control Act (MPCA), Environmental Agents Control Act (EACA). 
(2) Council of Agriculture (COA)

Pesticide Management Act (PMA), Feed Control Act (FCA).

(3) Department of Health (DOH)

Food Sanitation Management Act (FSMA).

(4) Council of Labor Affairs (COLA)

Labor Safety and Health Law (LSHL).

(5) Ministry of Economic Affairs (MOEA)

Water Supply Act (WSA).

Due to their lipophilic (hydrophobic) properties, many pesticides readily accumulate in human tissue following the ingestion of contaminated foods, and may induce the so-called food chain biomagnification, posing both carcinogenic and endocrine disrupting effects (Pretty \& Hine, 2005). One of the main aims for the Food Sanitation Management Act (FSMA) is to ensure the sanitation, safety and quality standards for foods, food cleansers, food utensils, food containers and food packaging being sold, which were prescribed by the central competent authority (i.e., DOH). Under the authorization of the FSMA, the relevant regulations (i.e., the Residual Limits of Pesticides in Livestock and Poultry products, and the Standards for Pesticide Residue Limits in Foods) pertain to the regulatory management of pesticides in the common foods (e.g., meat, milk, egg, and crops).

After the admission of Taiwan to the World Trade Organization (WTO) on January 1, 2002, the central competent authority, the Council of Agriculture (COA), has planned several policies and also revised/promulgated related regulations to promote the ecological operation by minimizing the use of pesticides and synthetic chemicals for the sustainable development of Taiwan's agriculture. In this regard, there are two relevant laws pertaining to the regulatory management of pesticide in the pesticides and feeds: the Pesticide Management Act (PMA) and the Feed Control Act (FCA). Under the definition by the former act, passed in Jan. 1972 and recently amended in Jul. 2007, the term "prohibited pesticides" denotes any and all agro-pesticides prohibited by the central government in public announcement from being manufactured, processed, repackaged, imported, exported, sold or used. Since the early 1970s, some pesticides have been officially announced as prohibited ones, including aldrin, DDT, dieldrin, endrin, heptachlor, hexachlorocyclohexane, lindane and toxaphene. On the other hand, the central competent authority may perform safety assessment over the registered pesticides. If a pesticide endangers the health of human body or pollutes the environment, it could be designated as one of use-restricted pesticides (e.g., 2,4-D, carbosulfan, endosulfan, isoprocarb, malathion, methamidophos, methomyl, paraquat and parathion). It is well known that acute pesticide poisoning led to significant impact on the public health system. Thus, the highly hazardous pesticides, including carbofuran, methamidophos, methomyl and paraquat, have been declared by the central competent authority. Regarding the FCA, passed in Jan. 1973 and recently amended in Jan. 2002, this Act is established to maintain the quality of feeds and to promote the development of the animal husbandry and the aquaculture industry so as to protect the public health. Under the authorization of the Article 20 in the FCA, the central competent authority thus promulgated the Pesticide Residue Limits in Feeds on 17 January 2008. Some pesticides, including aldrin, benzene hexachloride (BHC), carbaryl, chlorpyrifos, DDT, dieldrin, malathion and heptachlor, have been designated as chemical targets in the Limits.

\subsection{Recommendations for Pesticide Use}

To balance the agricultural practices, food safety and environmental protection, and also encourage the farmers to adopt integrated pest management and/or organic farming system as a measure for the reduction of pesticides, and further achieve the government goal (i.e., a vision of toxin-free Taiwan) in the near future, the following measures are recommended and enhanced:

-Promote the implementation of natural pesticides or natural pest techniques, and increase the subsidies to farmers for using them.

-Raise the inspection rate for pesticide residues in agro-products, and declare these survey results to the public.

-Enhance the consumer's willingness to pay more for certified pesticide-free crop products, and arouse consumer from perceptions about food production.

-Expand the lists of prohibited pesticides based on the Pesticide Management Act and other important international policies or codes. 
-Train the farmers to use pesticides effectively, exchange information on pesticide registration, and adopt environment-friendly pesticides.

-Putting pressure on retailer (or supermarkets) to concern about pesticide residues by government agencies and civil society organizations.

\section{Acknowledgements}

This research was partly supported by NSC (National Science Council), Taiwan, under contract number NSC 99-2313-B-020-011-MY3 (Project title: Pretreatment of lignocellulosic wastes by phsphoric acid hydrolysis, and chemical activation of resulting residue for production of lignin-based carbon adsorbent).

\section{References}

Amaral-Mendes, J. J. (2002). The endocrine disruptors: A major medical challenge. Food and Chemical Toxicolology, 40, 781-788. http://dx.doi.org/10.1016/S0278-6915(02)00018-2

Council of Agriculture (COA). (2012). Annual report of Taiwan's agriculture (in Chinese). COA, Taipei, Taiwan.

Dent, D. (2005). Overview of agrobiologicals and alternatives to synthetic pesticides. In J. Pretty (Ed.), The pesticide detox: towards a more sustainable agriculture (pp. 70-80). London: Earthscan.

Environmental Protection Administration (EPA). (2008). National implementation plan of Republic of China (R.O.C., Taiwan) under the Stockholm Convention on Persistent Organic Pollutants (in Chinese). EPA, Taipei, Taiwan.

Hess, P. (2010). A sustainable development metric based on youth. International Journal of Sustainable Development and World Ecology, 17, 542-551. http://dx.doi.org/10.1080/13504509.2010.517673

Katsvario, T. W., Wright, D. L., Marois, J. J., \& Rich. J. R. (2007). Transition from conventional farming to organic farming using bahiagrass. Journal of the Science of Food and Agriculture, 87, 2751-2756. http://dx.doi.org/10.1002/jsfa.3002

Lydy, M., Belden, J., Wheelock, C., Hammock, B., \& Denton, D. (2004). Challenges in regulating pesticide mixtures. Ecology and Society, 9, 1-15.

National Council for Sustainable Development (NCSD). (2011). Annual report on sustainable development indicators (in Chinese). NCSD, Taipei, Taiwan.

Oluwole, O., \& Cheke, R. A. (2009). Health and environmental impacts of pesticide use practices: A case study of farmers in Ekiti State, Nigeria. International Journal of Agricultural Sustainability, 7, 153-163. http://dx.doi.org/10.3763/ijas.2009.0431

Pretty, J., \& Hine, R. (2005). Pesticide use and the environment. In J. Pretty (Ed.), The pesticide detox: towards a more sustainable agriculture (pp. 1-22). London: Earthscan.

Shyu, T. H., \& Lee, Y. H. (2006). Monitoring of groundwater for paraquat in Chunghua and Yunlin, Taiwan (in Chinese). Weed Science Bulletin, 27, 21-30.

Toleubayev, K., Jansen, K., \& Van Huis, A. (2011). From integrated pest management to indiscriminate pesticide use in Kazakhstan. Journal of Agricultural Sustainability, 35, 350-375. http://dx.doi.org/10.1080/10440046.2011.562036 